\title{
INFLUÊNCIA DA IGREJA CATÓLICA NA EDUCAÇÃO DO CORPO NA CIDADE DE PORTEIRINHA EM MINAS GERAIS
}

Wilney Fernando Silva ${ }^{1}$

Armindo Quillici Neto ${ }^{2}$

\begin{abstract}
RESUMO: A proposta deste artigo é investigar a influência da Igreja Católica nas práticas corporais localizadas na cidade de Porteirinha, MG, entre 1930 a 1945. Para a Igreja, a educação foi uma poderosa estratégia no que diz respeito à expansão e à manutenção da sua hegemonia, e, por meio da sua doutrina, ela propôs a educação corporal de crianças, jovens e mulheres para que pudessem somar forças à religião. Para a constituição dessa tarefa, foi realizada a análise de fontes documentais em livros de reuniões de professores, recortes de jornais, fotografias, livros de diversas paróquias e legislação educacional. Como resultado, pode-se afirmar que a educação do corpo dava suporte à educação da mente e da moral. Com isso, o esporte passou a ser um aliado interessante para uma proposta de um Estado e de uma Igreja que se diziam, dentro dos seus domínios, unitários, fortes e racionalizadores.
\end{abstract}

Palavras-chave: Educação. Educação do Corpo. Igreja Católica.

\section{INFLUENCE OF THE CATHOLIC CHURCH IN BODY EDUCATION IN THE CITY OF PORTEIRINHA IN MINAS GERAIS}

ABSTRACT: The purpose of this article is to investigate the influence of the Catholic Church on body practices located in the city of Porteirinha, MG, from 1930 to 1945. For the Church, education was a powerful strategy in terms of expansion and maintaining its hegemony, and, through its doctrine, it proposed the corporal

\footnotetext{
${ }^{1}$ Doutor em Educação pela Universidade Federal de Uberlândia - UFU (2018; Mestre em Educação pela Fundação Universidade de Itaúna/MG - UIT (2008) e especialista em Treinamento de Força e Personal Training pela Universidade Estadual de Montes Claros - Unimontes (2003). Licenciado e Bacharel em Educação Física pela Universidade Estadual de Montes Claros/MG - Unimontes (2002). Licenciado em Pedagogia pela Universidade de Franca - Unifran (2019). É professor efetivo no Instituto Federal de Educação, Ciência e Tecnologia do Norte de Minas Gerais (IFNMG) - Campus Avançado Porteirinha, MG, e atualmente ocupa o cargo de Diretor do Departamento de Ensino.

2 Doutor em Educação pela Universidade Estadual de Campinas (UNICAMP) em 2001. Mestre em Filosofia pela Pontifícia Universidade Católica de Campinas, PUCCAMPINAS, Brasil em 1994. Graduado em Filosofia pela Pontifícia Universidade Católica de Campinas, PUCCAMPINAS, Brasil em 1987. Atualmente é professor da Universidade Federal de Uberlândia, UFU, Brasil.
} 
education of children, youth and women so that they could add forces to the religion. For the constitution of this task, the analysis of documentary sources was carried out in books of meetings of teachers, newspaper clippings, photographs, catholic church books and educational legislation. As a result, it can be said that the education of the body supported the education of mind and morals. Therewith the sport became an interesting ally for a proposal of a State and a Church that were said to be unitary, strong and rationalizing within their domains.

Keywords: Education. Body Education. Catholic church.

\section{INFLUENCIA DE LA IGLESIA CATÓLICA EN LA EDUCACIÓN DEL CUERPO EN LA CIUDAD DE PORTEIRINHA EN MINAS GERAIS}

RESUMEN: El propósito de este artículo es investigar la influencia de la Iglesia Católica en las prácticas corporales ubicadas en la ciudad de Porteirinha, MG, desde 1930 hasta 1945. Para la Iglesia, la educación fue una poderosa estrategia en lo que se refiere a la expansión ya la expansión el mantenimiento de su hegemonía, y, por medio de su doctrina, propuso la educación corporal de niños, jóvenes y mujeres para que pudieran sumar fuerzas a la religión. Para la constitución de esta tarea, se realizó el análisis de fuentes documentales en libros de reuniones de profesores, recortes de periódicos, fotografías, libros de diversas parroquias y legislación educativa. Como resultado, se puede afirmar que la educación del cuerpo daba soporte a la educación de la mente y de la moral. Con eso, el deporte pasó a ser un aliado interesante para una propuesta de un Estado y de una Iglesia que se decía, dentro de sus dominios, unitarios, fuertes y racionalizadores.

Palabras clave: Educación. Educación del Cuerpo. Iglesia Católica.

\section{Introdução}

O presente trabalho tem como objetivo investigar a influência da Igreja Católica nas práticas corporais ${ }^{3}$ localizadas na cidade de Porteirinha, no norte de Minas Gerais, entre os anos de 1930 a 1945. O recorte temporal coincide com os primeiros quinze anos de emancipação política da cidade, bem como com a criação do Grupo Escolar

\footnotetext{
${ }^{3} \mathrm{O}$ termo prática corporal, aqui utilizado, abarcará as manifestações culturais que enfocam a dimensão corporal humana, tais como o esporte, a ginástica, a dança e os jogos. Também entenderemos que a prática corporal pode ser vivenciada no espaço escolar (de forma sistematizada) e fora (individual ou coletivamente, de forma informal ou realizada em associações ou clubes esportivos).
} 
João Alcântara, principal instituição educacional urbana, e com a instalação da sede da paróquia no município, ações estas que vão propiciar maior aproximação entre a Igreja e o poder público local.

O texto será dividido em três partes: na primeira, apresentaremos algumas legislações educacionais oficiais do período que balizaram as finalidades do ensino e ditaram o tom formativo e moralizante para crianças, jovens, homens e mulheres da época. Ao adentrar a instituição escolar, debruçaremos sobre a Educação Física, componente curricular obrigatório, que ajudou a moldar o corpo, discipliná-lo, tornálo forte e contê-lo, enfim, este componente fazia parte do projeto político almejado para a nação brasileira. A educação corporal dava suporte à educação da mente e da moral, deste modo, o corpo higienizado, cívico e docilizado deveria ser preparado para uma nova forma de sociabilidade em que as regras esportivas barrassem o ímpeto e os instintos naturais humanos.

No entanto, se o componente político ditou os caminhos da educação, o religioso traçou a maneira de se caminhar. Assim, mostraremos, na segunda parte do trabalho, como as manifestações do sagrado, os símbolos e os valores católicos foram cultivados na cidade e no Grupo Escolar. Nestes espaços, a instituição eclesiástica exerceu um papel direto no ordenamento e no modo das pessoas verem e estarem o mundo. Entenderemos como eram realizadas as principais alianças entre a Igreja e o Estado. Por fim, apresentaremos as considerações finais e as referências da pesquisa.

Para a constituição dessa tarefa, foi analisada uma ampla documentação histórica que apresentasse práticas, discursos, posturas e vivências das pessoas daquele tempo. Deste modo, utilizamos fontes documentais como livros de reuniões de professores, recortes de jornais locais e regionais, boletins escolares, livros de diversas paróquias, leis e decretos do poder executivo, fotografias e legislações educacionais regionais e nacionais. Para dar embasamento histórico-científico, foram utilizados os seguintes teóricos: Azzi (2011); Carvalho e Carvalho (2010); Lenharo (1986); Schwartzman, Bomeny e Costa (2000) e Soares (1994).

No início da década de 1940, o município de Porteirinha contava com uma população com pouco mais de 20 mil habitantes (IBGE, 1947) que almejava a ampliação dos espaços de escolarização primária. Para resolver esse pedido, a elite econômica e social de Porteirinha, mediante várias articulações políticas, transformou as três escolas distritais mistas no Grupo Escolar João Alcântara (ESCOLA MISTA DO DISTRICTO DE PORTEIRINHA, 1929). A instituição teve como finalidade diminuir o número de 
crianças em idade escolar que não recebiam instrução ${ }^{4}$ e educar, dentro dos padrões morais e católicos, este público. Assim, criado em 30 de junho de 1937, por meio do Decreto no 885, publicado no Diário Oficial de Minas Gerais (MINAS GERAIS, 1937, p. 217), e instalado meses depois, o Grupo Escolar, em seu primeiro ano de funcionamento, contava com 192 alunos, distribuídos em quatro classes, e quatro anos mais tarde, contabilizava 420 matrículas (GRUPO ESCOLAR JOÃO ALCÂNTARA, 1946). A instituição, na época, representava a maior e era a principal instituição educacional primária da cidade.

É importante registrar que, ao elegermos o local como perspectiva de abordagem histórica no norte de Minas Gerais, mais especificamente a cidade de Porteirinha e o Grupo Escolar João Alcântara, estabelecemos uma fronteira onde algo começou a se fazer presente: sociabilidades diversas, em temporalidades e territorialidades variadas, que passaram a ganhar formas retratadas pela escola, pelos jornais e pela Igreja nesta localidade, imersa em transversalidade das mais diversas dimensões (políticas, educacionais, religiosas, culturais etc.). Nestes termos, a ênfase sobre a história local não se opõe à história global, ou seja, "o recorte sobre história local apenas designa uma delimitação temática mais ou menos inclusiva em função das particularidades que se queira determinar, no âmbito do espaço social e temporal escolhido" (CARVALHO; CARVALHO, 2010, p. 79).

Portanto, compreender os domínios da História da Educação é visualizá-los em um campo de múltiplas dimensões, as quais abrigam o regional, e este se insere no interior de um cenário espacial e temporal mais amplo e geral, que dialoga com as propostas e discussões no âmbito nacional e internacional. Assim, não nos propomos a fazer História da Educação regional, mas uma História da Educação brasileira com ênfase no regional.

\section{A educação physica e a formação corporal no grupo escolar}

Diálogo entre a professora Dona Olívia e seus alunos:

- Maria, a que se assemelha o corpo? - É semelhante a uma planta, porque cresce.

- Mário, qual é a sua opinião?

- Creio ser parecido com um automóvel, porque anda.

- Evocê, Jaime, que pensa?

\footnotetext{
${ }^{4}$ De acordo com o Recenseamento Geral do Brasil de 1940, 72\% das pessoas de Porteirinha, MG, não sabiam ler e nem escrever (IBGE, 1950, p. 430).
} 
- Penso que o corpo se assemelha a uma casa, porque... porque o edificamos.

(REVISTA VIDA E SAÚDE, 1941, p. 16).

No final dos anos 1930, conforme estudos de Lenharo (1986), surgiram inúmeras revistas especializadas em saúde, higiene, esportes e Educação Física. $\mathrm{O}$ corpo estava na ordem do dia e sobre ele se voltavam as atenções de médicos, políticos e professores. Instituições como o exército, as igrejas e a escola tomaram consciência de que pensar a sociedade para transformá-la passava necessariamente pelo trato do corpo como recurso de se alcançar toda a integridade do ser humano.

No excerto acima, o diálogo entre professora e alunos explora imagens comparativas de diferentes percepções do corpo. A planta que cresce remete para a condição natural do corpo humano, resposta que cabe, no texto, a uma menina educada presumivelmente para assumir a sua função de reprodutora de corpos e, portanto, conhecedora mais íntima dos movimentos naturais da geração e do crescimento. O automóvel que anda reporta ao domínio da cultura, ao nível do corpo maquinizado, mercadoria útil, modelada radicalmente pela própria ação humana. $\mathrm{O}$ corpo como casa edificada gera uma imagem que se sobrepõe às outras e joga ênfase sobre a moderada elaboração cultural e moral da casa-família. Ambas as trilhas, que derivam da terceira imagem, acabarão por nortear a condução de um discurso pedagógico, através do qual a professora aconselha o cuidado pessoal com o próprio corpo e demonstra a repercussão social das práticas higiênicas individualmente aplicadas (LENHARO, 1986).

Esse discurso pedagógico procurou cultivar um corpo belo, forte, saudável, higiênico, ativo, ordeiro e patriótico, em contraposição àquele considerado feio, fraco, doente, sujo e preguiçoso. Nas escolas, era preciso, pois, edificar o corpo das crianças e da juventude.

A Constituição Brasileira de 1937, promulgada por Getúlio Vargas, em seu artigo 15, fixava as bases, determinava os quadros da educação nacional e traçava as diretrizes a que devia obedecer a "formação physica, intellectual e moral da infancia e da juventude". O artigo 131 estabelecia: "A educação physica, o ensino civico e o de trabalhos manuaes serão obrigatorios em todas as escolas primarias, normaes e secundarias, não podendo nenhuma escola de qualquer desses gráos ser autorizada ou reconhecida sem que satisfaça aquela exigência" (BRASIL, 1937, p. 12). O currículo escolar serviu de apoio ao projeto de unidade nacional. 
Naturalmente, a postura oficial do governo era a de apoiar as práticas corporais. O artigo 132 da Constituição assegurava:

O Estado fundará instituições ou dará o seu auxílio e proteção às fundadas (referindo-se aos estabelecimentos educacionais) por associações civis, tendo umas e outras por fim organizar para a juventude períodos de trabalho anual nos campos e oficinas, assim como promover-Ihes a disciplina moral e o adestramento físico, de maneira a prepará-la ao cumprimento dos seus deveres para com a economia e a defesa da Nação (BRASIL, 1937, p. 13).

Seguindo os passos da Magna Carta, a Constituição do Estado de Minas Gerais, de 1947, também propiciava a mobilização de práticas corporais na escola. Seu artigo 131 rezava que:

Art. 131. O Estado estimulará e fiscalizará a prática da educação física e dos desportos em todo o seu território.

Parágrafo único. São obrigatórios os exercícios ginásticos em todas as escolas públicas ou particulares (MINAS GERAIS, 1947, p. 22).

A escola era um local privilegiado de difusão das práticas corporais de crianças e da juventude, e a Educação Física, cada vez mais, passava a ocupar um lugar consolidado no currículo das escolas do país. Em 1949, a professora de Educação Física do Grupo Escolar João Alcântara, ao fazer o resumo de suas atividades para o boletim mensal, declarou "a disciplina é provocada por meio da religião, ministrado aos alunos, tornando-os doceis e obedientes. Não encontrei dificuldades de ordem disciplinar" (GRUPO ESCOLAR JOÃO ALCÂNTARA, 1949, p. 34). A professora completa e finaliza, "os alunos concentrados e atenciosos, executaram bem os exercícios de ginastica e aprenderam as regras de alguns esportes. Todas as vezes que o Grupo apareceu em público nas demonstrações e competições, arrancou sempre as mais acaloradas aclamações" (GRUPO ESCOLAR JOÃO ALCÂNTARA, 1949, p. 34).

A Escola e o Estado procuravam assegurar a responsabilidade em formar os corpos e fortalecer sua ação sobre o preparo físico. Durante todo o percurso escolar, crianças e juventude passavam por um processo educacional pautado pela higiene, pela disciplina e pela docilização corporal. Como postula Lenharo (1986, p. 77), "o corpo passa a ser um produtor de moralidade, pois ele produz os padrões morais desejados pelo Estado. Além disso, ao mesmo tempo em que o corpo é produtor de uma moralidade, ele passa também a ser um transmissor dela".

Partindo do corpo, o Estado traçou uma identidade física, uma uniformidade para o brasileiro, dando sentido e forma à população pela educação moral, mas 
também pela Educação Física. Tudo isso garantiria a unidade desejada e, ao mesmo tempo, assegurava o futuro nacional e da raça (LENHARO, 1986).

Sobre essa suposta raça, é importante dizer que os anos 1930-1940 se caracterizaram, em boa parte da Europa, pela discussão da eugenia e da constituição de uma raça pura e forte que encarnasse o imaginário de nação ideal. Essa busca da identidade nacional, personificada pelas elites políticas e sociais, através da construção de uma raça símbolo, também se fez presente no Brasil durante o Estado Novo. É ilustrativo o texto contido nas atas de Conferências sobre Educação Física, de 1942:

A nova educação física deverá formar um homem típico, que tenha as seguintes características: talhe mais delgado que cheio, gracioso de musculatura flexível, de olhos claros, ágil, pele são, ágil, desperto, ereto, dócil, entusiasta, alegre, viril, imaginoso, senhor de si mesmo, sincero, honesto, puro de atos e de pensamentos, dotado com senso da honra e da justiça, comparticipando no companheirismo dos seus semelhantes, e levando o amor da Providência e dos homens no seu coração (XAVIER, 1999, p. 35).

Além de branco e belo, as elites econômicas e políticas afirmavam que o homem precisava ser forte para suportar o ritmo do trabalho diário, viril para gerar mais brasileiros eugenizados e dócil para colaborar com as intervenções do Estado (de referência, sem resistências). O melhoramento da suposta raça, todavia, implicava questões não apenas de ordem biológica, mas, principalmente, questões de ordem moral, como bons costumes e bons hábitos, inclusive sexuais.

Conforme aponta Oliveira (2008), em 1939 foi fundado o primeiro time de Futebol da cidade de Porteirinha, o Porteirinha Futebol Clube. O jornal Gazeta do Norte estampou um convite à população de toda a região para participar da nova agremiação:

O homem de hoje precisa enfrentar a vida de outro modo. Precisa dispor de outros recursos, é indispensavel prepará-lo não apenas intelectual e moralmente, mas fisicamente. Urge robustecer o homem, aprimorar-Ihe o fisico, assegurar-lhe o equilibrio organico, dota-lo de condições especiais, enfim, torná-lo forte sob o triplice aspecto: fisico, moral e intelectual.

Portanto, as diretrizes do Clube tendem a estimular a juventude na pratica dos esportes, procuram propagar os fins morais e sociaes das atividades fisicas e despertar a atenção publica para esse aspecto do problema educativo, coadjuvando com o programa de governo, de aperfeiçoar e engrandecer a nossa raça. Portanto, ó mocidade gloriosa, dirigi as vossas atenções para estas diretrizes, procurai cooperar com esta agremiação para o engrandecimento de vós mesmos engrandecendo desta maneira o nosso país (GAZETA DO NORTE, 1943b, p. 4). 
Destacamos como o desenvolvimento e a disciplina do corpo tiveram acepção em bases eugênicas e de melhoramento de uma suposta raça brasileira. Veja que o jornal apresenta as diretrizes do time, postuladas no ideal do novo brasileiro. 0 Porteirinha Futebol Clube tinha como objetivos robustecer o homem, aprimorar o físico, torná-lo forte e assegurar o equilíbrio orgânico. Ao participar do clube, o sujeito cooperava com sua saúde física e moral, mas, também, com a agremiação e com o país.

Aos olhos da população, a fundação de um clube de futebol marcaria o início da difusão dessa prática em Porteirinha. Circunscrito inicialmente aos integrantes da elite da cidade, o futebol, o voleibol (ver Figura 1) e outros esportes foram recebidos com empolgação.

Figura 1 - Time de Voleibol masculino de Porteirinha

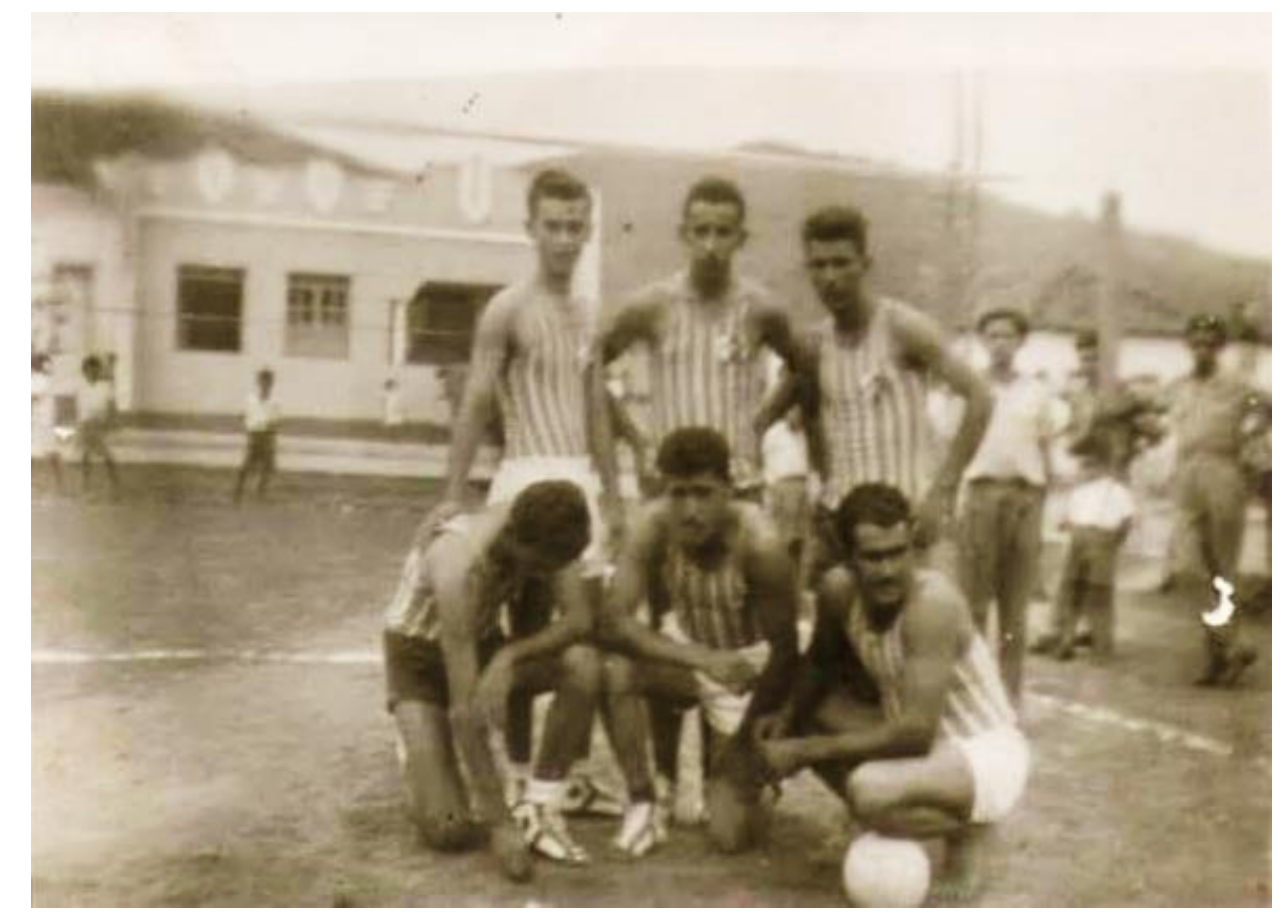

Fonte: CIDADE MINEIRA. Porteirinha. Galeria de fotos, 2016. 1 fotografia. Disponível em: http://www.cidademineira.com.br/galeria_fotos.php. Acesso em: 10 abr. 2016.

Oliveira conta como eles foram inseridos na cidade:

Em 1940, a cidade passou a contar com uma caixa de areia para saltos de altura; e também com um campo para prática do basquetebol [...]. O Voleibol era praticado diariamente, sempre com boa assistência, no pátio da Escola. Os praticantes dessa modalidade esportiva, na época eram: José Gomes de Oliveira, Antonio Nunes da Silva, Olegário Bonfim e seu irmão José Bonfim, Anfrísio Coelho e seu irmão Antímio Coelho, Alcebino Santos (Major) e Waldeck Cardoso (OLIVEIRA, 2008, p. 90, grifo nosso). 
Além de ser o lugar da formação do corpo das crianças, a escola ainda atendia à juventude local. Com o desígnio de "propagar os fins morais e sociaes das atividades físicas", os membros da elite ${ }^{5}$, devidamente uniformizados, reuniam-se ali para a prática esportiva. No dizer da época, o esporte poderia contribuir para a importante tarefa de refrear os vícios e a vadiagem, aprimorar a moral e o comportamento adequado.

Ao público feminino, o Gazeta do Norte, em 1943, noticiava o valor das práticas corporais, bem como as vantagens da política eugenista:

A educação fisica feminina é o primeiro capitulo de toda a regeneração fisica. Na reconstrução que está passando o Brasil, no afan de conduzir e preparar uma juventude sadia e otimista, a ginastica feminina se impõe como coadjuvante poderoso da eugenia. Ela visa antes de mais nada, a saude. E a saude é que há de mais precioso para o ser mortal, e para a mulher é uma necessidade. A educação fisica da mulher visa a obtenção do vigor organico, aumentando-Ihe a resistencia, colocando-a em melhores condições de lutar eficazmente contra as enfermidades. Visa a destreza, adquirindo habitos musculares e nervosos adaptaveis á vida pratica, e finalmente, como coroamento das qualidades precedentes, surge a qualidade que é o apanagio da mulher: a beleza (GAZETA DO NORTE, 1943a, p. 5).

Por trás desse discurso em que saúde e beleza eram imprescindíveis às mulheres, havia um sutil controle social acerca do melhoramento das qualidades raciais das futuras gerações. De acordo com Soares (1994), na época, a maternidade era fundamentada em princípios de higiene e eugenia. Os higienistas pregavam a "pedagogia da boa higiene", enquanto os eugenistas pregavam a respeito da boa procriação, estudavam a influência das heranças genéticas com relação às qualidades físicas e mentais dos indivíduos.

O forte espírito nacionalista da época corroborava com o pensamento de que a mulher deveria gerar filhos fortes que pudessem colaborar com o futuro da nação. Desse modo, os eugenistas, em conjunto com os higienistas, recomendavam que a mulher também deveria ser saudável e forte para poder gerar os filhos de igual característica. Esse discurso pode ser encontrado em outra edição do Gazeta do Norte:

Em todos os tempos o problema da regeneração humana nunca preocupou tanto os governos como agora. Os eugenistas têm se preocupado incessantemente em assegurar um futuro promissor ás gerações futuras. E,

\footnotetext{
${ }^{5}$ Anfrísio Coelho, Antímio Coelho e Alcebino Santos, por exemplo, foram poderosos chefes políticos na cidade. As fontes silenciam-se quando se trata das práticas corporais pelos membros das classes populares.
} 
para torna-las compostas de paz e de trabalho - só existe o recurso das praticas ditadas pela EUGENIA, as unicas que influem efetivamente sobre os elos da cadeia da vida representados pelas celulas da imortalidade da especie.

Cabe á mulher a conservação da especie no apuramento da raça; é da sua saude e do seu vigor que dependem ás gerações fortes, esplendidas, vitoriosas, que haverão de conduzir sempre com brilhantismo o facho luminoso de uma hereditariedade vigorosa através das gerações vindouras. A mulher precisa ser sadia, ser bela e ser forte e só uma educação fisica racional metodica e cientifica, ela encontrará os meios infaliveis e necessarios para obtenção dessas superiores qualidades. A mulher de hoje precisa, pois, praticar exercicios fisicos para conservar a sua juventude, a sua beleza, a flexibilidade das articulações, o equilibrio das formas, a frescura da pele, a rigidez dos musculos, o vigor dos orgãos e a capacidade de resistencia. Precisa, pois fugir da vida sedentaria e procurar as praças de esportes, os estadios, uma vida ao ar livre em competições alegres e sadias. É um dever para consigo mesmo e para com a Patria (GAZETA DO NORTE, 1944, p. 6).

O impresso faz uma vinculação da imagem feminina à obediência de algumas regras para o cuidado da saúde maternal. Faz também uma representação de uma mulher delicada e materna, que deveria cuidar da sua saúde para que pudesse cumprir o seu propósito: gerar, criar seus filhos e contribuir para uma formação de homens fortes e saudáveis para o "engrandecimento da raça e da Pátria". A Educação Física feminina seria o instrumento indispensável para este fim.

Além da necessidade de fortalecer seu corpo, a mulher precisava possuir um caráter de virtude, definido pela valorização de qualidades como a generosidade, a bondade, a decência e a abnegação (GOELLNER, 2003). Devido a isso, o zelar pela saúde era imprescindível, pois ela era vista como necessária para que a mulher fosse bela e estivesse preparada, de todas as formas, para gerar um filho.

Para o pensamento da época, a eugenia era necessária para que os ideais pudessem ser descritos a partir da melhoria progressiva da espécie, fomento de uma boa geração, procriação hígida e/ou sadia, e aperfeiçoamento físico, intelectual e moral do indivíduo. Para isso, todas as pessoas seriam responsáveis por tal empreita. O jornal fazia esse chamamento à sociedade para a formação de uma boa geração:

Mães de familia, colaborai com estas diretrizes enviando vossos filhos e as vossas filhas em procura da chave da felicidade afim de ajustar-se ao fecho magno das harmonias. Procurai incutir nos vossos filhos os habitos cotidianos da educação fisica para que ela os acompanhe pela vida em fóra com a fonte enexaurivel de inestimaveis predicados fisicos e morais e se reproduzam pelas gerações vindouras, como uma poderosa colaboração de fortaleza da 
raça e engrandecimento da raça e engrandecimento do nosso Brasil. As mães fortes são as que fazem os povos fortes (GAZETA DO NORTE, 1944, p. 6).

Lenharo (1986, p. 79) dá o nome a esse movimento de corporativização, que "persegue obstinadamente não somente a configuração de um tipo físico único para o brasileiro, mas ambiciona-se também a definição de um só perfil racial, a ponto de ser estabelecida uma relação simples entre raça e Nação constituída". A importância do trato do corpo foi crucial e a projeção mesma de uma parte física e equilibrada com a espiritual dimensionou um conjunto social equilibrado, no qual as tensões e conflitos ficaram de fora de lugar pela natureza singular de sua constituição.

De uniforme branco e saias longas, algumas mulheres de Porteirinha se reuniam frequentemente para a prática de Voleibol, conforme a Figura 2.

Figura 2 - Time de Voleibol feminino de Porteirinha

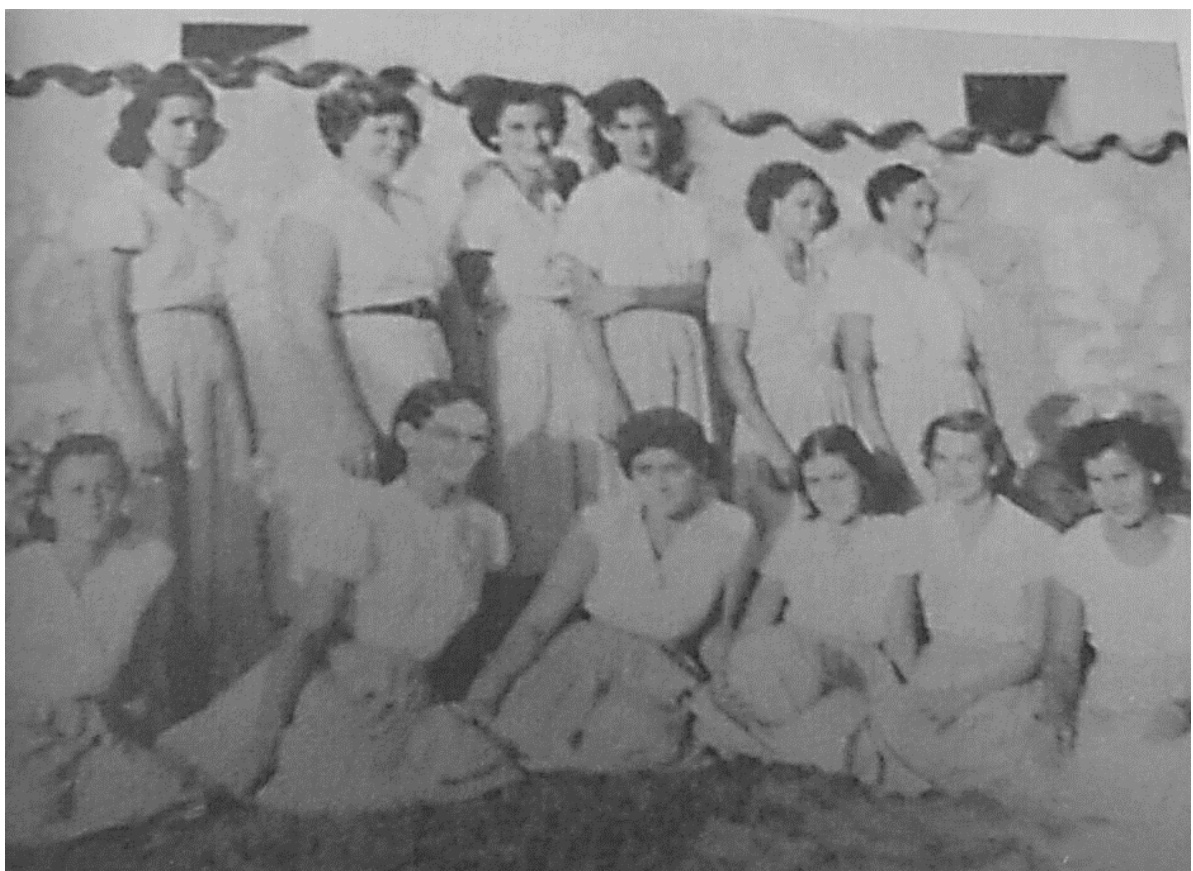

Fonte: OLIVEIRA, Palmyra Santos. Porteirinha: memória histórica e genealogia. Belo Horizonte: 0 Lutador, 2008, p. 91.

A memorialista Palmyra Santos Oliveira conta quem eram as participantes da equipe esportiva:

O time feminino contava com Dona Marocas Fonseca (esposa do prefeito Dr. Altivo), Hilda Martins Gomes (Dida), Raquel e sua irmã Belica Lacerda, Rita e 
sua irmã Marluce Gomes, Nadir Brito, D. Rola (esposa do Sr. José Clemente, fiscal da Prefeitura), Licinha e sua irmã Izene Coelho, Suzete Rosa de Brito, Geralda Nunes de Brito (Picucha), Bebete Cardoso, Jandira Machado, Lindalva Antunes da Silva, Bichim e Branca de Jovêncio, Dedésia Angélica Teixeira, Palmyra Santos Oliveira etc. (OLIVEIRA, 2008, p. 90, grifos nossos).

Conforme especificação da autora, as jogadoras eram mulheres reconhecidas socialmente e os nomes em destaque são das professoras do Grupo Escolar João Alcântara. Na fotografia, a expressão do recato corporal muito nos diz sobre o padrão moral posto em circulação. A beleza, a maternidade, a feminilidade e a saúde eram desejadas tanto pela mídia que as divulgava, quanto pela própria população, que em seu imaginário social identificava na mulher um meio para a modernização do país. Características como beleza, saúde, perseverança, dedicação, juventude, prudência e disposição deveriam se transformar em virtudes conquistadas diante da participação das mulheres na sociedade, inclusive nos locais onde eram realizadas práticas corporais e atividades esportivas (GOELLNER, 2003).

De forma geral, fortaleceu-se a crença de intelectuais e políticos de que a construção de uma nação e um Estado prósperos dependia, em grande parte, da tríade educação intelectual, moral e física dos sujeitos. A ação do Estado sobre a formação física da juventude de Porteirinha pode ser vista na Lei no 27, de 25 de fevereiro de 1949:

O povo do Municipio de Porteirinha por seus representantes legaes, decretou e eu, em seu nome, sanciono a seguinte lei:

Art. 1 - - Fica o poder executivo autorizado a doar à Associação Esportiva local a importância de CR $\$ 150,00$ (cento e cincoenta cruzeiros) mensais, cuja finalidade será o desenvolvimento físico da juventude local.

Art. 20 - Fica autorizada a abertura de um crédito especial no valor de CR\$1650,00 para ocorrer às despesas a que se refere o artigo 10 (PORTEIRINHA, 1949, p. 381).

Para a formação das crianças nos moldes daquela tríade, foi fundado o Grupo de Escoteiros de Porteirinha, em 1942. Segundo Horta (1994, p. 199), "o escotismo tinha como alvo educar o jovem na vida do grupo, em espírito e disciplina, contrapondo-se à aspiração de independência e inculcar nos jovens os princípios morais e católicos". O propósito desse movimento em Porteirinha foi potencializar as qualidades físicas, intelectuais, sociais, afetivas e espirituais das crianças e juventude e formar homens responsáveis e úteis. $\mathrm{O}$ grupo realizava atividades que tinham como pilares o civismo, entendido como "consciência patriótica", a educação moral como 
"elevação espiritual da personalidade" e a Educação Física (PORTEIRINHA, 1942, p. 268). Mediante o Decreto-Lei no 37, de 8 de novembro de 1942, o grupo começou a receber da prefeitura municipal subvenção anual de mil cruzeiros. Em discurso durante a fundação do Grupo de Escoteiros, o prefeito de Porteirinha, Altivo de Assis Fonseca, disse:

\begin{abstract}
É imprescindivel neste momento oferecer ás crianças e jovens do nosso glorioso Brasil uma orientação segura, fecunda e precisa. Orientação esta criadora de uma mentalidade espiritual superior, enaltecida no ideal grandioso da concepção mistica da Patria. O Grupo de Escoteiros veio para a cidade para ampliar as sublimadas tarefas da escola, e formar cidadãos disciplinados e saudaveis calcados nas mais elevadas normas e valores morais para o engrandecimento do nosso País (FONSECA, 1942, p. 1).
\end{abstract}

A educação nacional tinha como objetivo formar o homem completo, útil à vida social, pelo preparo e aperfeiçoamento de suas faculdades morais e intelectuais e atividades físicas, uma tarefa precípua da família e dos poderes públicos. A transmissão de conhecimentos seria sua tarefa imediata. Fazia ainda parte dos princípios gerais a definição do que se deveria entender por "espírito brasileiro", ou seja, a orientação baseada nas tradições cristãs e históricas da pátria, como foram mostrados no excerto anterior (SCHWARTZMAN; BOMENY; COSTA, 2000). Assim, um indivíduo que alcançasse uma qualidade superior física e psíquica não poderia se furtar a cumprir outro papel no interior da sociedade que não objetivasse outra finalidade eminentemente necessária: a de bem servir o Brasil.

De acordo com Azzi (2011, p. 105), "o adestramento corporal foi considerado um aspecto fundamental para facilitar o ingresso das pessoas na sociedade urbana. $A$ postura foi um elemento constitutivo do processo educativo". Esse aspecto foi fortalecido com as aulas de Educação Física e com a participação dos alunos nos desfiles cívicos. Desta feita, as manifestações patrióticas constituíram um poderoso instrumento utilizado a fim de mostrar à população local a importância da educação, capaz de conduzir centenas de crianças e jovens às ruas, em plena ordem e disciplina.

Em 1955, o padre Julião Arroyo Gallo6 ${ }^{6}$, vigário da cidade de Porteirinha, fotografou o desfile cívico de 7 de setembro que teve a costumeira participação dos alunos do Grupo Escolar João Alcântara, conforme mostra a Figura 3.

${ }^{6}$ Julião Arroyo Gallo nasceu no dia 6 de janeiro de 1904 em Burgos, na Espanha. Extremamente doutrinário, chega em Porteirinha em 1941 e articula-se com os poderes político, social e educacional. Foi um intelectual que recebeu uma educação melhor do que grande parte da população local e foi 
Figura 3 - Desfile 7 de setembro de 1955 em Porteirinha

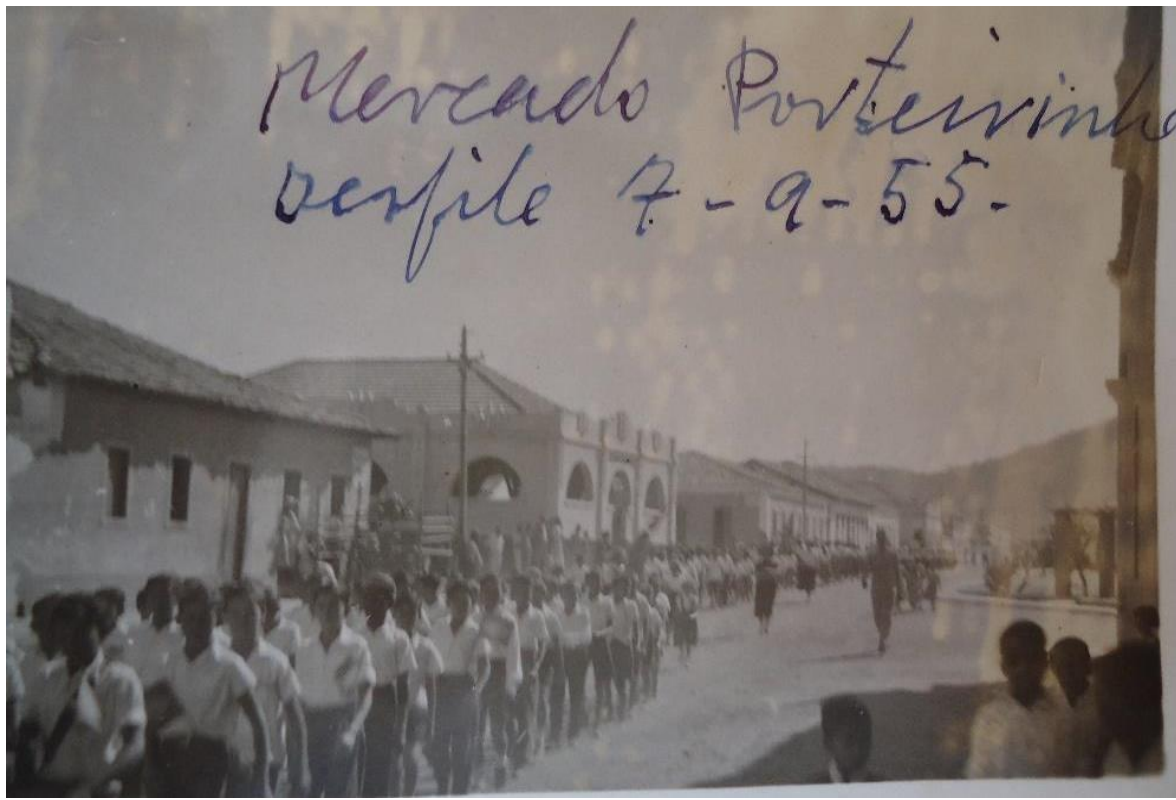

Fonte: GALLO, Julião Arroyo. Álbum de fotografias. Desfile 7 de setembro de 1955. 1 fotografia, Porteirinha, MG, setembro de 1955.

Nesses desfiles, o corpo devia ser conservado ereto, com os ombros puxados para trás e o peito enfunado para frente. Todos os movimentos deviam ser executados imediatamente, tão logo recebidas as ordens de comando. O corpo era adestrado para uma obediência imediata. Os alunos eram educados para prestar as homenagens aos símbolos nacionais, bem como às autoridades constituídas. Mediante rígidos movimentos do corpo, os alunos aprendiam a expressar sua decisão e servir à pátria, submetiam-se às autoridades superiores, às quais competia decidir sobre os rumos a serem dados na condução do país (AZZI, 2011).

Em outro episódio, em agosto de 1944, pela passagem da Corrida de Revezamento do Fogo Simbólico da pátria na cidade de Porteirinha, o prefeito Altivo de Assis Fonseca constituiu uma prestigiosa comissão para recepcionar a embaixada e promover a organização das solenidades cívicas para o dia 12 de agosto daquele ano. A comissão era composta por professoras do Grupo Escolar, servidores públicos e comerciantes (PORTEIRINHA, 1944, p. 196).

Segundo Rolim e Mazo (2009), a Corrida de Revezamento do Fogo Simbólico teve como data de início o ano de 1938 e surgiu como uma tradição enraizada no

uma das poucas pessoas que deixou escrito diversos textos localizados em jornais, livros institucionais da Igreja e manuscritos acerca dos aspectos sociais, políticos, culturais e educacionais da região. Gallo esteve à frente da paróquia de Porteirinha por quase trinta anos. 
período do Estado Novo. A Corrida iniciava-se por meio de uma cerimônia de acendimento da tocha, seguindo com a passagem da tocha aos atletas mediante um revezamento pelas cidades, até a chegada na cerimônia de acendimento da pira em Porto Alegre, durante a Semana da Pátria.

A Corrida estava inserida no processo de construção de uma identidade nacional brasileira proposta pelo Estado Novo. Essa tradição reforçava os laços de solidariedade entre os membros da sociedade e a partilha de mitos e memórias comuns na busca de construir uma representação de coesão ou unidade nacional no imaginário das pessoas. Essa representação se deu principalmente pelo formato de percorrer as cidades brasileiras (ROLIM; MAZO, 2009).

Em 1944, a passagem do Fogo Simbólico da Pátria em Porteirinha movimentou o Grupo Escolar João Alcântara e as associações esportivas locais. Os clubes esportivos deveriam demonstrar seu sentimento patriótico ao engajar-se nas atividades de recepção da embaixada e promover eventos esportivos com o objetivo de promover a "união das raças e dos brasileiros" (GALLO, 1944, s/p).

Auxiliado pelas professoras do Grupo Escolar, o padre Julião foi o responsável por planejar e organizar as comemorações patrióticas, a recepção de autoridades e atletas e as comemorações festivas, que incluíam as competições esportivas. Durante a recepção oficial da embaixada na cidade, o padre fez o seguinte discurso:

\begin{abstract}
Em nome do municipio, eu tenho a grande honra e a indisfarçavel satisfação de apresentar V. Excia. os nossos votos de boas vindas. [...] a população desta unidade mineira em formação, pedaço do sertão mineiro, orgulha-lhe por justo motivo da honrosa passagem. Primeiro, gostaria de registrar que o esporte é um eficaz antidoto contra a moleza e a vida comoda, acorda o sentido de ordem e educa ao exame e ao dominio de si, ao desprezo do perigo sem jactancia nem pusilanimidade. Assim, ele ultrapassa a robustez fisica para conduzir à força e à grandeza moral. A pratica esportiva é a proporcionadora de convivio social, instrumento de melhoria da saúde e fortalecimento da vontade coletiva, componentes representativos da boa conduta cristã. [...] Por fim, o esporte forma o novo homem, carregado de civismo, moral e patriotismo. O esporte forma o homem disciplinado, trabalhador e educado para o Brasil Novo (GALLO, 1944, s.p., grifo nosso).
\end{abstract}

No discurso, o pároco buscou realçar as intenções governamentais do projeto político da época ao citar a identidade cultural, construída a partir de um homem postulado pelo civismo, pela moral e pelo patriotismo. No entanto, fez uma interpretação do esporte mediante o olhar católico ao afirmar que a vivência esportiva 
é proporcionadora da boa conduta cristã. Na próxima seção, consta como as práticas corporais foram incorporadas à doutrina do catolicismo.

\section{O corpo que energiza a alma e fortalece a fé: esporte e Igreja Católica}

No excerto, o apóstolo São Paulo, no livro de Coríntios da Bíblia Sagrada (1990), fala do esporte e do cuidado do corpo. Por meio da metáfora da competição esportiva, ele põe em evidência o valor da vida, ao compará-la a uma corrida rumo a uma meta não só terrestre, mas transcendente e divina. Assim, o apóstolo convida os cristãos para se tornarem atletas de Deus, fiéis e destemidos anunciadores do Evangelho.

Vocês não sabem que no estádio todos os atletas correm, mas só um ganha o prêmio? Portanto, corram, para conseguir o prêmio. Os atletas se abstêm de tudo; eles, para ganhar uma coroa perecível; e nós, para ganharmos uma coroa imperecível. Quanto a mim, também eu corro, mas não como quem vai sem rumo. Pratico o pugilato, mas não como quem luta contra o ar (BíBLIA SAGRADA, 1Cor. 9, 24-27, 1990, p. 1399).

Para São Paulo, a prática dos esportes também pode levar o homem a Deus. Recorda o apóstolo:

Não sabeis que o vosso corpo é templo do Espírito Santo que está em vós, que vos foi dado por Deus e que não pertence a vós mesmos? Pois fostes resgatados por alto preço! Glorificai, portanto, a Deus no vosso corpo (BÍBLIA SAGRADA, 1 Cor. 6:19-20, 1990, p. 1399).

Conforme Werle e Metzler (2010), para a cultura cristã, o físico é uma representação da alma e dos níveis de aproximação com o transcendente, o primeiro passo para iniciar o processo de formação da pessoa e, neste caso, do futuro educador. O modelo de educação cristã, normatizado pela Igreja Católica, adotou a prática esportiva como mediadora dos princípios da fé caracterizada pelo convívio social, cuidado e disciplinamento do corpo para alcançar a espiritualidade.

Deste modo, a instituição religiosa teve interesse em participar diretamente da atuação, disciplinamento e moldagem dos corpos. Para ela, o esporte foi um instrumento capaz de agregar valores espirituais. Foi uma prática cultural capaz de espiritualizar a dimensão física, motora e biológica do homem. Enfim, para a Igreja, o esporte ajudava o homem a dignificar-se e elevar-se; seria um instrumento de anúncio da palavra de Deus.

Como ferramenta pedagógica, o esporte, desde o período colonial e imperial brasileiro, já estava presente pela iniciativa dos jesuítas e dos religiosos de outras 
ordens, em seus colégios. Em Montes Claros, a maior cidade do norte de Minas Gerais, por exemplo, a inserção do esporte pode ser atribuída à ação da ordem dos Premonstratenses. No início do século $X X$, o padre Vincart, um dos primeiros missionários belgas a chegar nesta cidade, utilizou o futebol como ferramenta para atrair os jovens e formar a população pela prática da modalidade esportiva (SILVA, 2012).

Uma das principais análises da Igreja Católica acerca das práticas corporais na época foi expressa pelo papa Pio XII, em 1945. Ao discursar para os jovens da Ação Católica naquele ano, o pontífice afirmou que "o esporte quando bem compreendido, representa a ocupação do homem completo, aperfeiçoando o corpo e o espírito, ajudando-o a alcançar o fim: o serviço de adoração do Criador" (GAZETA DO NORTE, 1945, p. 3).

Vejamos, com mais detalhes, as ideias da Igreja acerca da prática esportiva, amplamente divulgadas nos jornais locais:

\begin{abstract}
O Papa Pio XII diz que o esporte tem muito valor, mas em vez de ser considerado como um fim, deve ser considerado como um meio de aperfeiçoar o homem, intelectual, moral e fisicamente. $O$ esporte, adequadamente dirigido, desenvolve o caráter, torna o homem corajoso, um perdedor generoso e um vencedor gracioso. Refina os sentidos, dá penetração intelectual e fortalece a vontade de resistir. Não é apenas um simples aperfeiçoamento físico. [...] A serviço da vida sã, robusta, ardente, a serviço de uma atividade mais fecunda no cumprimento dos deveres do próprio estado, o esporte pode e deve estar também a serviço de Deus. Para este fim ele inclina os ânimos a dirigirem as forças físicas e as virtudes morais, que desenvolve; mas, enquanto o pagão se submetia ao severo regime esportivo a fim de obter somente uma coroa perecível, o cristão se submete a ele por um escopo mais alto, para um prêmio imortal (GAZETA DO NORTE, 1945, p. 4).
\end{abstract}

Para Pio XII, o esporte foi um componente mediador da evangelização plenamente integrado à doutrina católica. Suas palavras se aproximam da concepção de Educação Física que associa o esporte à saúde, mas, principalmente, ao bom comportamento. A saúde integra os componentes físicos e espirituais, enquanto que o bom comportamento se especifica no ideal de cristandade. O corpo não deve ser divinizado, mas melhorado, pois, segundo a visão religiosa, o que diferencia o homem do restante dos animais não era a força física, e sim a questão intelectual e espiritual. Então, como afirma Santo Agostinho, o trabalho do corpo deveria ser feito para 
melhorar o desempenho intelectual e, ao mesmo tempo, ajudar no sentido espiritual, já que a Igreja vê no corpo um simulacro do espírito7 (AGOSTINHO, 2000).

Para o pontífice, a Igreja se interessa pelas formas de educação do corpo, como o esporte, que tem uma importante função educativa:

O esporte moderno, conscienciosamente exercitado, fortifica o corpo, tornao são, forte e cheio de vida para executar esta função educativa; o esporte submete o corpo a uma disciplina rigorosa e por vezes dura, que o domina e o retém verdadeiramente em servidão: treino para a fadiga, resistência à dor, hábitos de continência e de temperança severa, condições todas indispensáveis para quem quer conseguir a vitória. Assim ele ultrapassa a robustez física para conduzir à força e à grandeza moral (PIO XII, 1953, p. 4).

O Catolicismo associou a formação educacional à fé e entendia o homem nos aspectos físico e psíquico, balizado pelo aspecto espiritual. Para a Igreja, a dimensão física estava centrada na experiência corporal e representava o primeiro estágio da pessoa, acreditando que o sentido transcendente da vida repercutia na forma pela qual se tratava e valorizava o corpo. A dimensão moral, associada ao processo de comunicação, tinha maior abrangência que a física, pois neste nível situam-se o processo de participação, integração e consciência. Já a dimensão espiritual, enquanto a fundamental, incluíam a busca de um sentido para a vida, a vivência religiosa e o diálogo com Deus (WERLE; METZLER, 2010).

O jornal $A$ Verdade trazia a concepção de "educação physica, intellectual e moral", e a valorização desta última:

Deveras, o desenvolvimento physico e intellectual do homem constitue um bem imenso, mas isso não basta - a vida moral lhe é indispensavel. Ella exige a formação da vontade, da consciencia e do coração; ella encerca os costumes, isto é, os habitos, os usos e toda a conducta do homem. [...] Mas esta educação moral deve ser religiosa - pois não ha verdadeira moral sem religião! (A VERDADE, 1907, p. 3).

\footnotetext{
${ }^{7}$ A ideia do corpo enquanto simulacro do espírito vem do pensamento agostiniano. Santo Agostinho aprende com os platônicos que uma explicação somente materialista ou corporalista do ser humano não dá conta da experiência humana. "Do platonismo, Agostinho assimilou a concepção de que a verdade, como conhecimento eterno, deveria ser buscada intelectualmente no mundo das ideias divinas". Por isso defendeu a via do autoconhecimento, o caminho da interioridade, como instrumento legítimo para a busca da verdade. Assim, somente o íntimo da alma, iluminada por Deus, poderia atingir a verdade das coisas (SUCHODOLSKI, 2002, grifo do autor). Em sua obra Confissões, o Bispo de Hipona diz "se a felicidade está em Deus, e não nos prazeres carnais, seria, então, o corpo um mal a ser evitado?".
} 
Esta mesma linha de pensamento é sustentada por Pio XII, em 1952, quando discursa para professores de Educação Física, em Roma:

Quando se respeita com cuidado o teor religioso e moral do desporto, ele deve entrar na vida do homem como elemento de equilíbrio, de harmonia e de perfeição, e como ajuda eficaz para o cumprimento dos outros deveres. Baseai, portanto, a vossa alegria na prática correta da ginástica e do desporto. Levai para o meio do povo a sua benéfica corrente para que prospere cada vez mais a saúde física e psíquica e se fortifiquem os corpos ao serviço do espírito; acima de tudo, enfim, não esqueçais, no meio da agitada e inebriante atividade gímnico-esportiva, aquilo que na vida vale mais que todo o resto: a alma, a consciência e, no vértice supremo, Deus (PIO XII, 1953, p. 13-14).

Para o papa, "o desporto e a ginástica devem não mandar e dominar, mas servir e ajudar. É a sua função, e nisso encontram a sua justificação" (PIO XII, 1953, p. 8). Para finalizar a análise, ele conclui: "quereis agir retamente na ginástica e no desporto? Observai os mandamentos de Deus!" (PIO XII, 1953, p. 14).

Em Porteirinha, durante a abertura do Campeonato Esportivo Intermunicipal, em novembro de 1941, que envolveu esta cidade e a de Grão Mogol, o padre Julião disse aos atletas e à comunidade:

Servindo-se do esporte, hoje foi dado um passo importante que ambiciona congregar todos os cidadãos de Porteirinha e Grão Mogol aqui presentes. Queremos que o espirito de lealdade, entusiasmo, cordialidade e fraternidade façam com que este evento transcenda a competição esportiva e se torne um passo a mais na construção de homens fortes, retos e civicos. O "Porteirinha Sport Club" dá um passo proficuo no desenvolvimento da cultura fisica neste local; mas não é só isso, esta ação propicia a agradavel construção de laços de camaradagem e união. Sabemos que o esporte é de grande necessidade, e entra hoje em quase todos os programas do ensino. $O$ esporte desenvolve os musculos, ativa a circulação, aprimora os traços, modifica os gestos, castiga os habitos e priva o vicio, entrelaça e une corações amigos e forma o caracter! (GALLO, 1942, s.p.).

Ainda em seu discurso, o padre deixou explícita a concepção católica acerca do esporte:

sobre o esporte, queridos atletas, a bôa religião diz: "prestai em primeiro lugar a Deus a honra que Lhe é devida, e sobretudo, santificai o dia do Senhor". Deste modo, a pratica do desporto não dispensa ninguem dos deveres religiosos e de participar da missa. Não se esqueçam tambem que o Criador quer harmonia e afeto no seio da familia. Recorda, pois, a fidelidade às obrigações familiares que se devem preferir às supostas exigencias do desporto e das associações desportivas (GALLO, 1942, s.p.). 
O olhar tridentino sobre o esporte e a ginástica chegou em Porteirinha pelo padre Julião, e parece que a prática corporal se integrou à cultura da fé. No Grupo Escolar João Alcântara, as vivências corporais, como a iniciação ao esporte, os jogos e as danças, eram conteúdos fundamentais. As práticas corporais estavam presentes em diversos tempos e espaços escolares: a iniciação esportiva estava presente no Futebol; danças eram ensaiadas para as apresentações nos auditórios; os jogos eram realizados durante as excursões; e com a finalidade de abrilhantar as comemorações patrióticas na cidade, a professora de Educação Física treinava exercícios e números ginásticos para serem exibidos nas apresentações públicas (GRUPO ESCOLAR JOÃO ALCÂNTARA, 1946; 1956).

Estas ações estavam em conformidade com a legislação oficial. A Lei Orgânica do Ensino Primário, Decreto-Lei no 8.529, de 2 de janeiro de 1946, assegurava que era finalidade deste nível de ensino "proporcionar a iniciação cultural que a todos conduza ao conhecimento da vida nacional, e ao exercício das virtudes morais e cívicas que a mantenham e a engrandeçam" (BRASIL, 1946, p. 1). A Educação Física, enquanto componente curricular obrigatório, tinha muito a oferecer a esse modelo de formação cívica e moral das crianças e da juventude.

No entanto, se o componente político ditou os caminhos da educação, o religioso traçou a maneira de se caminhar. Escreveu a professora de Educação Física do Grupo Escolar sobre um dia esportivo da programação da Semana da Criança, em 1952:

[...] pela manhã, antes de sairmos para a Igreja, ensinei aos alunos lições de proceder bem na rua e a obediência que deveriam ter às minhas ordens, treinando-os moralmente. Na Matriz, todos se comportaram e lembraram dos bons modos e das regras de respeito e educação. À tarde, houve um entusiasmado e festivo jogo de futebol entre as classes do Grupo. Antes das partidas, foi entoado o Hino Nacional, e no início de cada jogo, os alunos rezavam pedindo saúde e a vitória. Notei que os meninos colocavam em prática o espírito de cordialidade, da boa vontade, energia e a alegria de viver. No final, após ser servida uma farta merenda, li a mensagem: "busquem trabalhar e ganhar medalhas, mas, sobretudo, busquem o principal trofeu da vida: Deus" (GRUPO ESCOLAR JOÃO ALCÂNTARA, 1952, p. 15).

As práticas corporais foram revestidas de elementos religiosos. A professora ensinava os modos de comportamento, os preceitos morais vigentes e uma racionalização do corpo para a fé que envolvia posturas, gestos e condutas. Veja que 
uma parte do tempo escolar e das atividades envolviam a Semana das Crianças e fora dedicada ao agradecimento a Deus. Os alunos, por sua vez, compreendiam esta mensagem, e colocavam em prática manifestações cristãs, como as orações antes do jogo e a consagração a Cristo pela vitória alcançada.

O discurso, sem dúvida, faz-nos lembrar o diálogo entre a professora Dona Olívia e seus alunos, descrito no início da seção. As diversas manifestações corporais presentes em Porteirinha permitiram-nos pensar a construção de corpos na perspectiva de fazê-los crescer, desenvolver e reproduzir, como pensa a aluna Maria. Homens e mulheres a buscar tornar seus corpos mais limpos, mais produtivos, moralmente eficazes, um corpo pensado como uma máquina que produz, como justifica Mário. Também fez-nos imaginar o corpo como uma casa que precisava ser edificada, como aponta o discente Jaime. Nesse aspecto, o corpo, submetido à ação modeladora dos poderes originários da família, do Estado e do Catolicismo, tomou contornos e caminhos que o conduziu e o edificou sob o solo da moralidade. Enfim, a formação de homens inteligentes, fortes, cívicos, disciplinados e dóceis a partir da educação e da Educação Física foi almejada e os discursos pedagógicos revelaram vestígios e nos permitiram decifrar as vivências cotidianas, a rede de sociabilidade e as posturas. Corpos que falam, que energizam a alma e fortalecem a fé.

\section{Considerações finais}

A educação do corpo na cidade de Porteirinha, MG, procurou assegurar a responsabilidade em formar os corpos e fortalecer sua ação sobre o preparo físico. Crianças e juventude foram educados, higienizados e moldados pelo Grupo Escolar João Alcântara.

A disciplina procurou docilizar os corpos para melhor serem aproveitados pelo projeto do governo brasileiro, que buscou formar um novo brasileiro. Esse processo também abarcou as mulheres, pois nele estava presente a representação de uma mulher delicada e materna que deveria cuidar da sua saúde para que pudesse cumprir o seu propósito: gerar, criar seus filhos e contribuir para uma formação de homens fortes e saudáveis para o engrandecimento da raça e da Pátria.

A Igreja Católica também fez uma interpretação do esporte e se propôs a participar diretamente da atuação, disciplinamento e moldagem dos corpos. Segundo a Igreja, a vivência esportiva era proporcionadora da boa conduta cristã. O esporte e a 
Educação Física foram instrumentos de valores espirituais, ou seja, formaram uma prática cultural capaz de espiritualizar a dimensão física da criança e do jovem.

O Grupo Escolar, em especial, valorizava e idealizava a dimensão moralizadora no ensino. O governo, por sua vez, esperava contar com o apoio de todas as forças morais. Junto à Igreja Católica, a escola era um dos meios para sanear o ambiente moral de Porteirinha e também do Brasil. As práticas desenvolvidas no interior daquele espaço escolar podem ser compreendidas como produtoras de sentidos e identidades. Estes sentidos, de certa forma, foram sedimentados pela inserção do catolicismo na escola pública.

Por fim, ao concluir a apresentação dos resultados da investigação, os dados revelam vestígios e nos permitem decifrar as vivências cotidianas, a rede de sociabilidade, as posturas e os códigos compactuados. Explicita-se, deste modo, que a temática desenvolvida no trabalho é bastante atual e perene. Deste modo, questões como "Ensino Religioso nas escolas públicas", "Projeto Escola sem Partido", "Laicidade e influência da religião nos diversos espaços" chegam aos dias de hoje e, com bastante força, são discutidas nas câmaras legislativas, no senado e em vários lugares que se debatem políticas educacionais.

\section{Referências}

AGOSTINHO, Santo. Confissões. São Paulo: Nova Cultural, 2000. [Coleção Os Pensadores].

A VERDADE. A Educação Moral (Papel do Pae de Familia). v. 1, n.25. Montes Claros/MG, 2 de dezembro de 1907, p. 2-4.

AZZI, Riolando. A Igreja Católica na Formação da Sociedade Brasileira. 9. ed. Aparecida: Santuário, 2011.

BÍBLIA SAGRADA. Bíblia Sagrada: edição pastoral. 34. ed. São Paulo: Paulus, 1990.

BRASIL. [Constituição (1937)]. Constituição da República dos Estados Unidos do

Brasil. Rio de Janeiro, 10 de novembro de 1937. Disponível em <http://www2.camara.leg.br/legin/fed/consti/1930-1939/constituicao-35093-10novembro-1937-532849-publicacaooriginal-15246-pl.html>. Acesso em: 17 out. 2017.

BRASIL. Decreto-Lei no 8.529, de 2 de janeiro de 1946, Lei Orgânica do Ensino Primário. Rio de Janeiro, 2 de janeiro de 1946. Disponível em: <http://www2.camara.leg.br/legin/fed/declei/1940-1949/decreto-lei-8529-2-janeiro1946-458442-publicacaooriginal-1-pe.html>. Acesso em: 26 ago. 2016. 
CARVALHO, Carlos Henrique de; CARVALHO, Luciana Beatriz de Oliveira Bar de. História/historiografia da educação e inovação metodológica: fontes e perspectivas. In: COSTA, Célio Juvenal Costa; MELO, Joaquim José Pereira; FABIANO, Luiz Hermenegildo. Fontes e métodos em história da educação. Dourados/MS: UFGD, 2010, p. 79-110.

CIDADE MINEIRA. Porteirinha. Galeria de fotos, 2016. 1 fotografia. Disponível em: <http://www.cidademineira.com.br/galeria_fotos.php>. Acesso em: 10 abr. 2016.

ESCOLA MISTA DO DISTRICTO DE PORTEIRINHA. Livro de acta de exames e termo de promoções da escola mista do distrito de Porteirinha. Grão Mogol/MG, 1929.

FONSECA, Altivo de Assis. [convite]. Grupo de escoteiros na cidade. Destinatário: ao povo de Porteirinha. Porteirinha, MG, 1942. 1 convite.

GALLO, Julião Arroyo. Álbum de recortes de jornais. Esportes em Porteirinha. Porteirinha, MG, 17 de dezembro de 1942.

GALLO, Julião Arroyo. Álbum de recortes de jornais. O Brasil Novo. Porteirinha, MG, 10 de setembro de 1944.

GALLO, Julião Arroyo. Álbum de fotografias. Desfile 7 de setembro de 1955. 1 fotografia, Porteirinha, MG, setembro de 1955.

GAZETA DO NORTE. Educação Fisica Feminina. Montes Claros/MG, 20 de fevereiro de $1943 a$, p. 5.

GAZETA DO NORTE. O futebol. Montes Claros/MG, 21 de setembro de 1943b, p. 4.

GAZETA DO NORTE. A importância da Educação Fisica para a mulher. Montes Claros/MG, 7 de dezembro de 1944, p. 4.

GAZETA DO NORTE. O esporte é um meio de aperfeiçoar o homem. Coluna Vida Católica. N. 1618. Montes Claros/MG, 30 de agosto de 1945, p. 3.

GOELLNER, Silvana Vilodre. Bela, maternal e feminina: imagens da mulher na Revista Educação Physica. Ijuí/RS: Unijuí, 2003.

PORTEIRINHA. Boletins Mensais dos registros escolares do Grupo Escolar João Alcântara. GRUPO ESCOLAR JOÃO ALCÂNTARA. Porteirinha, MG, 1944 a 1955.

PORTEIRINHA. Livro de atas de exames, termos de promoções, de instalação da escola desta cidade e dos termos de visitas dos srs. Assistentes Técnicos. GRUPO ESCOLAR JOÃO ALCÂNTARA. Porteirinha, MG, 01/02/1946 a 16/07/1954.

PORTEIRINHA.GRUPO ESCOLAR JOÃO ALCÂNTARA. Livro de atas de exames, termos de promoções, de instalação da escola desta cidade e dos termos de visitas dos srs. Assistentes Técnicos. Porteirinha, MG, 1946. 
PORTEIRINHA.GRUPO ESCOLAR JOÃO ALCÂNTARA. Livro de atas das reuniões das professoras do Grupo Escolar João Alcântara. Porteirinha, MG, 1956.

BRASIL. INSTITUTO BRASILEIRO DE GEOGRAFIA E ESTATÍSTICA (IBGE). Anuário Estatístico do Brasil. Ano VII - 1946. Rio de Janeiro, 1947.

BRASIL. INSTITUTO BRASILEIRO DE GEOGRAFIA E ESTATÍSTICA (IBGE). Recenseamento Geral do Brasil de 10 de setembro de 1940. Série Regional - Minas Gerais, Tomo 1. Censo Demográfico, população e habitação. Rio de Janeiro, 1950.

LENHARO, Alcir. Sacralização da Política. 2. ed. São Paulo: Papirus, 1986.

MINAS GERAIS. Decreto $n^{\circ} 885,30$ de junho de 1937. Cria um grupo escolar no distrito de Porteirinha, municipio de Grão Mogol. Diário Oficial de Minas Gerais, Poder Executivo, Belo Horizonte, 30 jun. 1937, p. 217.

MINAS GERAIS. [Constituição (1947)]. Constituição do Estado de Minas Gerais. Belo Horizonte: Assembléia Legislativa do Estado de Minas Gerais, 1947.

OLIVEIRA, Palmyra Santos. Porteirinha: memória histórica e genealogia. Belo Horizonte: O Lutador, 2008.

PIO XII, Papa. Sobre o desporte e a educação física. (Documentos Pontifícios). Petrópolis, São Paulo: Vozes, 1953.

PORTEIRINHA. Decreto-Lei no 37, de 8 de novembro de 1942. Dispõe sobre concessão de subvenções, contribuições e auxílios.

PORTEIRINHA. Livro n. 1 de Leis e Decretos da Prefeitura Municipal de Porteirinha. Porteirinha, MG, 2 de janeiro de 1939, p. 268.

PORTEIRINHA. Prefeitura Municipal. Comissão de recepção da Embaixada do "Fogo Simbolico", ano de 1944. In: GALLO, Julião Arroyo. Álbum de recortes de jornais. Porteirinha, MG, 1944, p. 196.

PORTEIRINHA. Lei no 27, de 25 de fevereiro de 1949. Dispõe de doação financeira à Associação Esportiva local. Livro n. 1 de Leis e Decretos da Prefeitura Municipal de Porteirinha. PORTEIRINHA, MG, 25 de fevereiro de 1949, p. 381.

REVISTA VIDA E SAÚDE. Para meninos e meninas. Santo André/SP, v. 3, n. 11, novembro de 1941, p. 16.

ROLIM, Luís Henrique; MAZO, Janice Zarpellon. A corrida de revezamento do fogo simbólico da pátria em Porto Alegre (1938-1947): estudo sobre a participação dos clubes esportivos. Movimento. Porto Alegre, v. 15, n. 4, p. 11-33, out./dez., 2009. SCHWARTZMAN, Simon; BOMENY, Helena Maria Bousquet; COSTA, Vanda Maria Ribeiro. Tempos de capanema. 2. ed. São Paulo: Fundação Getúlio Vargas; Paz e Terra, 2000. 
SILVA, Luciano Pereira da. Em nome da modernidade: uma educação multifacetada, uma cidade transmutada, um sujeito inventado (Montes Claros, 1889-1926). 2012. Tese (Doutorado em Educação) - Universidade Federal de Minas Gerais, Belo Horizonte, 2012.

SOARES, Carmen Lúcia. Educação Física: raízes Europeias e Brasil. 2. ed. Campinas: Autores Associados, 1994.

SUCHODOLSKI, Bogdan. A pedagogia e as grandes correntes filosóficas: a pedagogia da essência e a pedagogia da existência. São Paulo: Centauro, 2002.

WERLE, Flávia Obino Corrêa; METZLER, Ana Maria Carvalho. Missão evangelizadora: mediações da prática esportiva. Revista História da Educação, v. 14, n. 32, set./dez., 2010, p. 199-219.

XAVIER, Libânia Nacif. O Brasil como laboratório: educação e ciências sociais no projeto do Centro Brasileiro de Pesquisas Educacionais. Bragança Paulista: EDUSF, 1999. 